International Journal of Child, Youth and Family Studies (2013) 1: 147-165

\title{
A CONTEXT OF DOMESTIC VIOLENCE: LEARNINGS FOR PREVENTION FROM THE CALGARY FILIPINO COMMUNITY
}

\author{
Lana Wells, Debb Hurlock, Marichu Antonio, Vic Lantion, \\ Rida Abboud, Caroline Claussen, and Liza Lorenzetti
}

\begin{abstract}
There is a lack of interpretive research in the domestic violence literature and, in particular, within an ethnocultural context. Interviews were held with four Filipina women in Calgary, Alberta who had previously been in violent relationships, in combination with a referral group of key informants with leadership and knowledge of community issues related to domestic violence. By adopting a phenomenological approach to the research, it was hoped that new understandings of what is identified in clinical paradigms as the "risk" and "protective" factors associated with domestic violence would be unearthed. This research study is at once exploratory and informative and is intended to contribute to the development of a province-wide plan to address and prevent domestic violence through the Brenda Strafford Chair in the Prevention of Domestic Violence at the Faculty of Social Work, University of Calgary.
\end{abstract}

Keywords: domestic violence prevention, ethnocultural communities, Filipino, phenomenological approach and domestic violence

Acknowledgements: We gratefully acknowledge our research participants, women and men from the Filipino Community in Calgary, who bravely stepped forward to share their stories and insights with us. Without you, this research would not be possible. This project was made possible through funding from the Centre for Criminology and Justice Research (CCJR), which contributes independently produced, evidence-based research in the study of criminal and social justice issues and the promotion of safe communities.

Lana Wells, MSW is the Brenda Strafford Chair in the Prevention of Domestic Violence at the University of Calgary, 2500 University Drive NW, Calgary, Alberta, Canada, T2N 1N4.

E-mail: lmwells@ucalgary.ca

Debb Hurlock, Ph.D. is a research consultant in Calgary, Alberta. Her area of expertise is communitybased research. E-mail: dhurlock@creativetheoryconsulting.com

Marichu Antonio is the Executive Director of the Ethno-Cultural Council of Calgary.

E-mail: Marichu.ethnoculturalcouncil@gmail.com

Vic Lantion is the Community Programs Manager of the Ethno-Cultural Council of Calgary.

E-mail: vic.lantion@ecccalgary.com

Rida Abboud is a Ph.D. candidate at the Factor-Inwentash Faculty of Social Work at the University of Toronto.E-mail: rida.abboud@utoronto.ca

Caroline Claussen, M.A. is a research consultant in Calgary. E-mail: C3inc@shaw.ca

Liza Lorenzetti, MSW is a social worker and Ph.D. student at the University of Calgary, with over 20 years experience in domestic violence prevention. E-mail: lakoren@ucalgary.ca 
Canada's long history of immigration has created a diverse cultural mosaic. In 2006, the largest ethnocultural communities in Canada consisted of members from South Asian, Chinese, African-Canadian, and Filipino backgrounds (Statistics Canada, 2006). The diversity within the Canadian population warrants the attention of researchers (Wells, Abboud, \& Claussen, 2012) so that the voices and experiences of all Canadians can be acknowledged and considered in the creation of programs and social policy. According to Statistics Canada (2010) projections, by 2031:

- Between $25 \%$ and $28 \%$ of the population could be foreign-born.

- Between 29\% and 32\% of the population could belong to a visible minority group, as defined in the Employment Equity Act. This would nearly double the proportion reported by the 2006 Census.

- The fastest growing visible minority communities, due to immigration and births, are South Asian, Chinese, Black, Filipino, Arab, and South East Asian.

As reported in the 2004 General Social Survey on victimization, visible minority women report lower five-year rates of spousal violence than non-visible minority women. Moreover, self-reported rates of spousal violence declined for visible minority women between 1999 and 2004, whereas they remained stable for other women (Statistics Canada, 2010). It should be noted, however, that these lower rates could be attributed to the fact that the General Social Survey is conducted in English and French, and may in fact under-represent the actual rates of domestic violence in communities where women cannot participate due to language barriers (Public Health Agency of Canada, 2008). Brownridge and Halli (2002) reported that immigrant women from developing countries had the highest prevalence of Intimate Partner Violence (IPV) in Canada, followed by Canadian-born women, and thirdly, immigrant women from developed countries who exhibited the lowest rates of domestic violence.

In the United States, population-based, epidemiological research also suggests that immigrant women in particular have lower rates of domestic violence incidence than their American-born counterparts (Yoshihama, 2009). However other community-based investigations have documented high partner victimization rates among immigrant women (Gupta, 2009; Yoshihama, 2009). Evidently, it is difficult to gauge in existing literature the actual extent and prevalence of domestic violence in ethnocultural communities. Despite the lack of accurate information on the rates of domestic violence in ethnocultural communities, the fact that immigrants, refugees, and visible minority communities are a growing segment of the Canadian population provides a rationale for the development of culturally-responsive prevention strategies (Lorenzetti \& Este, 2010; Smith, 2006).

\section{Definitions}

Unfortunately, social science research tends to blend or aggregate broad "racial" categories, regardless of ethnicity, immigration status, or country of origin (Yoshihama, 2009). While the term "ethnocultural communities" is used throughout this paper, it is important to acknowledge that it is often used interchangeably with “visible minority communities". Visible minorities are, according to Smith (2006): “persons, other than Aboriginal peoples, who are non- 
Caucasian in race or non-white in colour" (p. 5). Although many ethnocultural communities have multi-generational Canadian identities, this study focuses on the intersecting issues presented by the participants' experiences of migration to and settlement in Canada, as well as other identity constructs. Research indicates that being foreign-born or "native"-born, intersected by belonging to a visible minority community, has a significant impact not only on acculturation but on the experiences of domestic violence in host countries (see Ahmad, Driver, McNally, \& Stewart, 2009; Grewal, Bottorff, \& Hilton, 2005; Gupta, 2009; Guruge, Khanlou, \& Gastaldo, 2010; Kasturirangan, 2008; Sharma, 2001). By definition, an immigrant is an individual who has acquired legal status to reside in Canada, including permanent residents, visitors, and students (Smith, 2006). The broad category of immigrant, utilized frequently in domestic violence prevention literature, does not distinguish or highlight one's migratory experience (Lorenzetti \& Este, 2010 ). For example, "refugee” is also a legal resident in Canada, although their premigratory experiences may have been quite different from that of other immigrants.

\section{Domestic Violence Risk and Protective Factors}

In regard to areas relevant to prevention, the literature points to a number of domestic violence risk and protective factors that are particular to the experiences of visible minority and/or immigrant women. The consequences and implications of engaging in the immigration process are important when considering the risk and protective factors of domestic violence (Jolly \& Reeves, 2006; Tutty, Giurgiu, Traya, Weaver-Dunlop, \& Christensen, 2010). Moreover, the experiences of visible minorities in Canada, as it relates to exposure to discriminatory practices, racism, employment and housing marginalization, settlement and acculturation, can also impact domestic violence as either a cause or effect. It is imperative that the migration experiences and migrant status of women be taken into account, and that the experiences of all "women of colour" not be generalized. Recent immigrants and refugees, although possibly also members of visible minority groups, face particular contextual circumstances that may pose as risk and protective factors for domestic violence (Gupta, 2009; Jolly \& Reeves, 2006). These circumstances may include: marginalization in the workplace, social isolation, immigration status, or trauma and stress as a result of home country conditions. For example, a Canadian study by Lorenzetti and Este (2010) highlights the multiple impacts of war, state violence, or other forms of trauma, including forced migration, on refugee women's experiences of resettlement and domestic violence.

Visible minority women, who may or may not be foreign born, contend with being labelled the cultural "Other" in Canada. In the context of domestic violence and visible minority women, there is a need for a nuanced analysis about how the experiences of these women are defined by their status as racialized and nationalized others. For example, this sort of analysis exposes how the cultural values of women in ethnocultural communities may be at odds with dominant North America society and culture, for example with respect to the importance of family preservation over individualism and the desire for independence (Almeida \& DolanDelvecchio, 1999; Sharma, 2001). Thus, prevention efforts that espouse a particularly Eurocentric feminist and/or self-empowerment approach, as defined by a dominant ethnocentric paradigm and directed toward ethnocultural communities, may be lost in translation (Kasturirangan, Krishnan, \& Riger, 2004; Kasturirangan, 2008). As stated by Sharma (2001): 
[feminist battered women's movements]... leads to conflict between fulfilling one's own needs and satisfying the needs of others. Although this struggle is also experienced by White battered women, it is more intense for immigrant and racially visible battered women because of their strong connections to their racial and ethnic heritages. (p. 1412)

This understanding would also shed light on why immigrant and visible minority women may hesitate to report abuse and/or leave abusive situations. A woman's disclosure of domestic violence can lead to a rejection from her intercultural support network, thrusting her into a mainstream culture that does not accept her "otherness” (Kasturiangan et al., 2004; Sharma, 2001; Smith, 2006).

An understanding of the family structures, including extended family, of immigrant and/or visible minority women may also shed more light on the factors leading to or preventing domestic violence (Tutty et al., 2010). Social networks in immigrant and ethnocultural communities can be key to protecting the family from a variety of social ills, including domestic violence. Such networks often provided instrumental, informational, emotional and psychological support (Guruge et al., 2010; Kasturiangan et al., 2004; Sharma, 2001). However, many women leave these forms of social networks in their home countries to face smaller, sometimes non-existent social supports, which propel them into domestic violence vulnerability. Tamil participants in a study conducted by Guruge et al. (2010) note that even if there are family members in Canada, the values that may have structured the perceived or expected support have changed due to the influence of an individualistic society. Interestingly, in the same study, women who had their own family members in Canada felt more protected from violence in the household. However, when they did not have their own family members nearby but were in close proximity to their husbands' family members, there was an increase in both the husbands' power over their wives and abuse from the extended family.

Finally, several studies (Guruge et al., 2010; Jolly \& Reeves, 2006; Kasturiangan et al., 2004; Smith, 2006) report that many women find it stressful to the family unit when their husbands and other men from their community experience racism and discrimination in the workplace and in mainstream society, usually in the form of under-employment and/or a lack of accreditation of their foreign credentials. Regardless of whether driven by patriarchal ideological values or not, this downward financial and professional mobility, with a perception that it is beyond their control, leads to a loss of social status at home and in the community. Guruge and colleagues (2010) state:

Our findings, along with those of a number of previous studies, show that postmigration factors operating at the macro-level of society, including economic insecurity resulting from non-recognition of professional/educational credentials, workplace deskilling and racial/ethnic discrimination - added to the patriarchal pressure for men to meet family and social responsibilities - pushed men to selfand family-destructive behaviours. (p. 110) 
International Journal of Child, Youth and Family Studies (2013) 1: 147-165

It is important to note that the immigration process has a significant impact on immigrant men as well. For example, research indicates that refugee men who flee their homelands after witnessing torture, war, political imprisonment, and other forms of violence may exhibit violent behaviours as a means of solving problems, dealing with their own trauma and stress, and expressing their feelings of disempowerment and loss of control (Gupta, 2009; Guruge et al., 2010; Lorenzetti \& Este, 2010). A study by Gupta (2009) highlights that men reporting premigration political violence exposure were over twice as likely to report any past-year partner violence perpetration.

\section{Research Background and Approach}

The Brenda Strafford Chair in the Prevention of Domestic Violence at the University of Calgary was created to lead and facilitate an initiative called "Shift: The Project to End Domestic Violence”. Shift is a community-based project aimed at significantly reducing and eventually ending domestic violence in Alberta. The name Shift represents the spirit of this initiative aimed at creating transformational change using a primary prevention approach to stop the first-time victimization and perpetration of domestic violence. In short, primary prevention means taking action to build resilience and prevent problems before they occur.

In order for Shift to be successful, it is necessary to work with citizens, community organizations, and experts to gather information on the scope of domestic violence in Calgary and in other Alberta localities. Generating a more comprehensive understanding of the risk and protective factors of domestic violence, particularly with respect to immigrant, refugee, and ethnocultural communities, is a critical part of this work. In examining the diversity trends for Calgary, the largest immigrant source country is currently the Philippines ${ }^{1}$, with India in second place (City of Calgary, 2009). There is a need to better understand domestic violence and the opportunities for its prevention for members of the city's largest immigrant source country. The following research study presents findings from a sample of individuals from the Filipino community in Calgary.

\section{Research Approach with the Filipino Community}

The researchers engaged in two-hour individual interviews with four research participants. The research was approved by the University of Calgary Ethics Board. The interviews took place over one month in February 2011 with four Filipina women, all of whom had experienced domestic violence within the past five years. The interviews were held at a nonprofit organization in Calgary where the Ethno-Cultural Council of Calgary is located. All research participants were recruited through the Ethno-Cultural Council. The four women who participated in the research chose pseudonyms: Red, Jennifer, Shine, and Jocelyn. Red's and Shine's experiences of domestic violence predominantly occurred while living in the Philippines, yet its impact reverberated while they settled in Calgary. Jocelyn and Jennifer married Canadian Caucasian men in Calgary and their experiences of domestic violence began while living in Calgary. In using a phenomenological approach, each interview with the Filipina women was

\footnotetext{
${ }^{1}$ In 2008, there were 1,907 immigrants landing in Calgary from the Philippines. This represents a $27.1 \%$ increase from 2007 (City of Calgary, 2009).
} 
thematically analyzed and interpreted as an individual narrative. According to Flyvberg (2001), analyzing the information in this way "produces precisely the type of context-dependent knowledge which makes it possible to move from the lower to the higher levels in the learning process” (p. 71).

Given the contextual factors to consider when conducting research with (a) the Filipino community, and (b) the topic of domestic violence, it was critical to work with ethnocultural community leaders who understood the cultural nuances of the community. Having a community liaison - the Executive Director of the Ethno-Cultural Council of Calgary, who shared the information about the research study and circulated the recruitment notice - assured the Filipino community that the research was ethical, safe, and intended to help build the capacity of the community. This approach draws on the tenor of engaging in community-based research that honours the community organizations that already work in the field of domestic violence, yet are seeking research to better understand how to end it. Domestic violence is a taboo topic within the Filipino community, and it would have been very difficult to engage people in qualitative research without having a respected connection to a leader in that community.

\section{The Lived Experience of Domestic Violence}

The capacity to articulate new meanings about domestic violence is derived from a deep history of research, practice, and theories of domestic violence and social change. Research in domestic violence and prevention has been primarily informed by "structural processes" (Denzin 1984, p. 487) that shape and influence violence. These structural analyses tend to be more commonly found in the clinical and social science paradigms of criminology, social work, social justice, and psychology. Turning to the lived experience of violence of four Filipina women constitutes exploratory research and is unique in the field of domestic violence research; it is intended to offer and invite different kinds of questions and ways of thinking about how domestic violence is rendered. To understand the phenomenon of domestic violence it is important to understand what happens within the lived experience of violence, and to recognize that the topic itself comes with a history, and predominant ways of being seen. There is a desire for a renewed understanding of domestic violence that can occur by engaging unique research methodologies that will inform prevention work differently, for the purpose of transformational social change.

In order to build a renewed understanding of the risk and protective factors for domestic violence within the Filipino community, this study used a phenomenological approach. Moran (2000) states that the "enduring influence of phenomenology is the manner in which it steadfastly protected the subjective view of experience as a necessary part of any full understanding of the nature of knowledge” (p. 21); in the case of this research, the subjective view constituted a full understanding of domestic violence in the context of the first-hand experience of Filipina Canadians in Calgary. A phenomenological approach enabled the researchers to describe the phenomenon as it appears in the lives of these Filipina women. Thus, descriptions about domestic violence were not imposed before the phenomenon had been understood from within (Moran, 2000). This enabled a discovery-oriented approach to understand the interior experience of violence. 
International Journal of Child, Youth and Family Studies (2013) 1: 147-165

\section{Supporting the Lived Experience: Conversations with Filipino Men}

In order to support the findings gleaned from the interviews with the key informants, the second part of this research study was a focus group with men from the Filipino community who are community leaders. This referral group of key informants reinforced the learning from the interviews. Filipino men who had directly perpetrated violence were not willing to participate in the research ${ }^{2}$. Thus, in order to elicit male Filipino perspectives on domestic violence, the focus group was held comprised of seven Filipino men who are community leaders and provide informal support to men who have either perpetrated violence, or been victims of violence. The focus group was facilitated by a male Filipino member of the research team as the Filipino men were not comfortable or willing to talk with one of the female researchers.

\section{Findings}

\section{Domestic Violence is a Process, Not an Event}

In talking with the four Filipina women, the researchers quickly learned that the experience and topic of domestic violence could not be extracted and dissected from their lives. It is contextual; it is a living process that is compounded, negotiated, contested, and mitigated by a variety of influences. So, to understand domestic violence, there is a need to understand the women, to hear their life stories and how violence weaves through them. The researchers were reminded that domestic violence is not an event, it is a process; it is an experience that weaves through people's lives daily. There are moments and experiences that may propel a person to change and, as one participant explained, it is also something that "you just live with". It is naïve for researchers to think that interviews could extract or pull out the topic of domestic violence from the lives of participants. In each individual narrative, as the participants began to talk about their migration process to Canada, they wove their experiences of domestic violence throughout the interview. The researchers quickly realized that the way in which the research participants were talking about their experiences of family, of being Filipina women, of work, and of their migration process to Canada, revealed that domestic violence was a process threaded through all facets of their lives.

What motivates change for a person experiencing domestic violence? How does a person choose renewal amid her own rooted history? For the interview participants, their renewal of a violence-free life was for multiple reasons: It was one's Roman Catholic faith; or the inspiration and love of one's children; or attending a local gym and finding the athlete she once was; or a

\footnotetext{
${ }^{2}$ The original intent for this research was to conduct individual interviews with Filipina women and Filipino men. However, due to the apparent discomfort of men in discussing this topic and therefore the inability to recruit participants, a Filipino male member of the research team suggested that we engage with a referral group of key leaders who had knowledge of community issues related to domestic violence. "One of the factors that is most often said to affect the access, gathering and analysis of information is 'gender', another factor is 'ethnicity"” (Fortier, 1998, p. 48). The researchers considered this encounter as a learning opportunity for research with ethnocultural communities, yet, at the same time agreed with Fortier (1998) in not wanting to identify gender and ethnicity as "fixed social categories, but rather...lived differently in different contexts... and rather than identifying how gender and ethnicity affect the research process, we need to examine how they are negotiated” (p. 49).
} 
International Journal of Child, Youth and Family Studies (2013) 1: 147-165

friend telling her that she is worth it, and beautiful; or returning to meaningful work; or her physician, saying "it’s time to go for your own safety".

What are the vulnerabilities that may precipitate domestic violence? This was not an easy question for the participants to answer, particularly when not wanting to essentialize certain aspects of Filipino culture as "risk factors" for violence, yet also needing to understand what commonalties existed for Filipina women that may have precipitated domestic violence. Further, what factors contribute to their survival? For the Filipino culture, it is essential to take into consideration the pre-departure experiences of people in their country of origin. How is violence expressed in the Philippines? What are Filipino norms for gender roles? How equitable are the political and economic structures?

We look to particular ethnocultural experiences of violence, and in the case of this research informants from the Filipino community, to produce new social knowledge about preventing domestic violence. Rather than situate violence within ethnocultural communities, we look to them to tell us something new about violence that will inform, or possibly mitigate prevailing forms of discourse. To see and hear something new, we need to ask something new, and ask different people about their experiences of violence.

\section{Women's Work and Filipina Women: A Process of Meaning-Making Amidst the Violence}

I give up my work and then you see, I give my resignation. - Participant \#1

My job is the only one who is supporting me. - Participant \#2

All four women, while living in either the Philippines or Canada, were the financial support for their husbands; two of the women supported their husbands while living in the Philippines, the other two participants financially supported their husbands while in Canada. The participants emphasized the cultural role of Filipina women to be the central caretaker of families in all facets of life, from the domestic to the financial. When they had to give up working, as one participant did to care for her in-laws' rural plantation, they felt that their own career goals were disregarded and invalidated. For another, when the violence was consuming her life, she still had her work to give her a sense of purpose and dignity. In this sense, work was explained as both confining and liberating, a movement from their private lives to feeling strength in their public lives. For one participant, it became the eventual means for her total independence, and influenced how she redefined family for herself:

Number one is because I changed my goal from family first. Because I don't have a family now. [My daughter] has her own life. I don't live with [my ex-husband] any more. So my goal is [to move] from family first to work first because my work, my job is the only one who is supporting me. Well I have friends, I have my family, but when it comes to financial I don't want to depend on anybody. I don't wanna go and move back to my brother-in-law...So my job is first.

Based on the narratives of the four Filipina women, work and training programs provided meaningful experiences that motivated them to not live in violent relationships. The meaning of 
work in the lives of women experiencing domestic violence may also be informed by the psychotherapeutic paradigm of finding a reason to live. This emerged from Frankl's (1984) work, in which he developed a psychotherapeutic paradigm of logotherapy to explain how some people continue to live and create meaning in life in spite of profound trauma. For one participant, work was a saving grace and involved returning to professional work in an urban centre as the context within which she experienced her "turn" from the violence in her life. Two other participants met and fostered friendships with women through the work context, who they turned to in their moments of need; it was these confidante friendships that provided the opportunity for the externalization of their struggles.

Another participant worked in a women's shelter and although support was offered to her, and she was involved in training to recognize violence, she still was unable to leave a highly violent relationship or seek support within her work context. However, through work she met someone she felt she could call when she decided to leave. One Easter Sunday, this participant experienced a traumatic episode of violence by her husband, in which she was taken to an Emergency Department and later admitted to the hospital for her injuries. She called her one friend:

But I don't have anyone here at that time. I was so new in this office too, and she became my friend right away. That was the only number I knew. She was the only person I knew. Because I had to call her not too long ago and suddenly the number came to my mind. I dialed that number, it was Easter Sunday too. Fortunately she was home, and all she said was "Where are you?" and I said, "I'm in the hospital", and I just started to cry. Then she said, "You don't have to talk, I can just be here on the phone, it's okay”. Because I didn't want any - I didn't want her to come.

This research contributes to an exploration of the meaning of work in the lives of Filipina women and how it may be both a limitation that creates vulnerability to violence, or how professional work, as in the case of the latter participant, is life saving.

\section{The Relationship of Migration, Settlement and Domestic Violence}

All four women had varying reasons for why they wanted to leave the Philippines. A common, general thread is that they wanted a better life. Had a family member not sponsored them, most Filipina women migrated through the Live-in Caregiver Program implemented in Canada in 1991. This program brings in thousands of Filipinos to Canada every year (Jiwani, 1997) ${ }^{3}$. One participant commented that she wanted to come to Canada to get away from an abusive husband and Canada was perceived to offer a better life:

\footnotetext{
${ }^{3}$ Canadian immigration policies have differential impacts according to gender, with research suggesting that some programs create vulnerabilities for human trafficking (Oxman-Martinez, \& Hanley, 2001). Two immigration programs in particular leave women vulnerable to trafficking: the Fiancée’s Visa and the Live-In Caregiver Program (LCP). For trafficked women arriving with such legal immigration documents, exploitation generally begins after they enter the country (Andrew, 1998). The result is a cycle of threats and abuse of all kinds: working for less than minimum wage, forced debt, violence against the trafficked individuals and/or their families (Oxman-Martinez, \& Hanley, 2001).
} 
International Journal of Child, Youth and Family Studies (2013) 1: 147-165

Philippines doesn't have much to offer, like especially when you don't have the education or something. And it's hard to get jobs there; even if you get a job, like I had a job, I could live, um, I could live within my means and just live with what we had, but then we wanted something better.

For two of the participants, leaving the Philippines was a way out of domestic violence. Once in Calgary, however, the unaddressed impacts of the violence in their lives while in the Philippines positioned them with a particular vulnerability for further violence. One of the participants stated that her father's violence was a motivating reason for her decision to come to Calgary:

But then, I also decided to come over [to Calgary] because my dad has been abusive to my mother since we were little. We have seen him batter my mother, knocked her down on the floor, took her to the hospital, bruises all over her and this is like almost every night, every night. My father, if my mom would be late for 15 minutes because of the traffic, he would think that okay, you've been having sex with another man....So I've seen my father abuse my mom so much since I was little, all the way since I left Canada and when they followed us here, he was still abusive but verbally not physical. So we threatened our father, if you do this you are going to be confined to Foothills Hospital.

Violence was present in another participant's extended family. Her mother-in-law came to stay with the participant and her family because her father-in law was abusive, yet they never spoke about it. She reflected on the time her mother-in-law came to stay with her briefly, and how, it is one of those things, that you just have to bear: "although you've already been abused, but still we go on...Yeah we have to bear with it...So that's why when I was there, that's why I've been suffering, because I realize that I've been abused for how many years". When her motherin law stayed with her, she began to realize that she too was being abused.

\section{Vulnerability for Violence: Family and Employed Caregiving}

Approximately 5,000 women per year have come to Canada to work as "live-in" domestic workers under the government's 1981-1992 Foreign Domestic Movement Program, and the current Live-in Caregiver Program, and a large number of these women are from the Philippines (Hodge, 2006). In 2011 alone, more than 5,200 visas were issued for live-in caregivers, with the majority being from the Philippines (Statistics Canada, 2011). One of the research participants was sponsored by her extended family and once in Calgary, she was the caregiver for her extended family that was very abusive. She did not see a connection between her previous violent husband and the domestic violence of her extended family. For this participant, there was a feeling that she "owed" her extended family for sponsoring her and that she was subsequently "owned" by them. One interview participant noted that they were "holding me in the neck. Like controlling me and everything I do". She continued to share how she felt mistreated by them:

I felt like I was a slave too, 'cuz I would do everything for them, cook for them and clean the house and they would come home and eat and relax and that was okay with me. 
International Journal of Child, Youth and Family Studies (2013) 1: 147-165

Because I just wanted to get it over with, I don't want to fight, but then they would not be pleased. They would never be pleased. Like I would cook and they would say something, "Oh this is too salty" [laughs], like little things like that. It is ridiculous.

As the abuse was perpetrated by family members, this participant felt an entrenchment of guilt: "I'm torn between leaving and not leaving because I'm thinking, "Oh these are my dad's sisters, this is my grandma". It was a hard decision, I stayed for more than two years there."

The social norms and political, cultural, and economic structures of a home country can significantly inform and change how a woman's migration process can be a positive or a further violating experience (Jolly \& Reeves, 2006). Two of the interview participants were live-in caregivers when they arrived in Calgary. One of them was a caregiver for an extremely oppressive and emotionally violent extended family that occasionally also resorted to physical violence. The other was initially a caregiver for her extended family, but was subsequently told to work for a non-familial employer in Lethbridge. Her new employers treated her with constant suspicion that she was stealing small material things. She felt vilified for things that she did not do, to a point where she decided to leave.

\section{The Traditions of Religion and Culture as Harmful and Supporting}

This research set out to begin discerning and understanding the factors that create situations that exacerbate people's vulnerabilities to violence. In this research, particular vulnerabilities began to emerge, yet when we looked at the whole of the women's lives, we learned that some of those vulnerabilities were also the supports or "protective factors". All four women stated that they were strong Roman Catholics, the dominant faith in Filipino culture. To varying degrees, all of them felt that their faith supported them through the violence. A patriarchal interpretation of Roman Catholic religion positions women as subservient to their families, to be constant caretakers. This was highlighted by the participants, as religion did perpetuate the entrapment of the women, and also contributed to them remaining in the abusive relationship. As one participant reflected, it is difficult to discern between what part of the violence is accepted tradition, and what is not: "How do you know that you already need help compared to what is traditional... some traditions tell you that that's okay, that's part of it". In the moments when another participant questioned whether she should leave, she commented that she would return to her faith and ask her God what to do, and she believed he wanted her to stay and follow her husband:

How could I go? I have my baby, but oh “Okay, Lord...I don't know”. I'm asking again, I just, I have faith in the Lord. I have a big faith first of all. I honour the Lord first, that is my guidance....So I'm always, I'm always "Yes Lord, yes Lord, I will follow my husband, I will be a good housewife, okay".

Yet, dedication to faith and family are also an integral support for healing. One participant confided in a pastor who offered support and another participant who was very religious talked about how important friends were in helping her heal: "We're all Roman Catholic. So if it helps them to go to church, if it helps to pray, then that's good too. I think it 
International Journal of Child, Youth and Family Studies (2013) 1: 147-165

helped me too". For a third participant, when she and her husband participated in Couples for Christ, it temporarily helped, although the domestic violence later emerged again.

\section{Findings from the Focus Group}

As noted previously, the Filipino male focus group was comprised of seven Filipino men who are community leaders and provide informal support to men who have either perpetrated violence, or been a victim of violence. The focus group was facilitated by a male Filipino member of the research team given that Filipino men were not comfortable or willing to talk with one of the female researchers.

The men talked about the unique ways that domestic violence emerges between couples in the Filipino community because of the strong, often patriarchal traditions of family, and a deeply rooted Roman Catholic religion. They stated that most domestic violence occurs in families that have been separated - one spouse is living in Canada and one in the Philippines and how the separation can often lead to infidelity. One participant noted, "for a husband or a wife, seeing oneself as the victim of infidelity, it's normal to commit violence in the family. Again, as I said, it's always the children who are the victims of this kind of violence". The Filipino men spoke of adjustment to the cultural norms of Canada, which is perceived as more permissive, contributing to seduction and infidelity on the part of their Filipina wives. Infidelity was discussed at great length as a precipitating factor of domestic violence. One declared:

Our cultural values as Filipinos, the only thing that a husband or wife would commit that is that is not forgivable is infidelity. That's the culture in our place in the northern part. So I mean your wife can tell you anything, everything: I will not cook for you, I will not care for you, as long as you will not commit infidelity, still ah, cling to her. But there's only one thing you should not commit. It's infidelity.

The group participants did not however, use this issue as a justification for domestic violence. Rather, they commented that because of the length of time it takes for a spouse to be sponsored, when they do finally arrive, often he or she may discover the "spouse or their husband is cohabituating with someone else".

\section{Migration and the Impact of Precarious Employment as Vulnerability for Violence}

The Filipino men discussed the impact of menial and precarious work in Canada, and how this is a significant stressor that may precipitate domestic violence. Part of the stress is the "culture shock" of arriving in Calgary and only being able to obtain a "menial” job after being a professional in their home country. Several studies point to the tremendous amount of stress to the family unit when husbands and other men from the community experience racism and discrimination in the workplace and in mainstream society, usually in the form of underemployment and/or lack of accreditation of their foreign credentials (Guruge et al., 2001; Jolly \& Reeves, 2006; Kasturirangan et al., 2004; Smith, 2006). This is one of the stressors of the migration process and the reality of the employment and lived experience of many Filipinos in Calgary, as one focus group participant explains: 
International Journal of Child, Youth and Family Studies (2013) 1: 147-165

They settle with working menial jobs and because they are not used to it, when they come home they are a bit stressed and, you know, here's [where] the finger pointing comes in, blaming each other, "why did you, you know, force me to come here? I had a good job there". So you know the pressure mounts.

The men discussed the need for "pre-departure orientation" sessions for men and women leaving the Philippines that realistically describe the experience of being a temporary foreign worker, and a live-in caregiver. Secondly, they identified the need to have information, both before departure and once in Calgary, about domestic violence and the supports available to address behavioural challenges within a relationship when settling in Calgary. A Filipino participant noted that prior to departure people are like "captive customers", thus it is an ideal time and place to offer the information. This may also help to mitigate the romanticized notion of Canada being a "Graceland” and thereby preparing migrants for a more realistic settlement experience in Canada.

\section{Discussion}

Although the sample size for both groups was small, it is difficult to summarize the rich, in-depth experiences shared in this study without seeming to reduce their complexity or impact on the lives of the participants. However, there are several poignant themes that should be highlighted in order to promote understanding, inform discussion, and further the aim of violence prevention in the community.

\section{Experience of Work and Domestic Violence}

There is a need for further interpretive research to better understand the meaning of work in the lives of Filipina women who experience domestic violence. Grossman and Chester (1990) argue:

Less attention has been given to the phenomenological experience of work for women; that is, studies that focus on how women view themselves as workers, how they experience their work and the meaning they make of it in the context of the rest of their lives. (p. 2)

"Work outside the home" was a central motivator for change for the four Filipina women. However, work can hold many meanings, and for the four Filipina women in this research, it held a double meaning. On the one hand, gender roles are to a great extent socially defined as within the home. Filipina women, like the following Taiwanese women:

were taught how to do housework and cooking, and how to manage family life. They were not allowed to have strong opinions, as they were wives, and they had been told to believe that within a marriage their husbands and children were their whole life - that is to say, they had no rights as individuals in marriage....the woman should selflessly supply her husband and children with all she could. (Williams \& Yu, 2006, p. 64) 
International Journal of Child, Youth and Family Studies (2013) 1: 147-165

On the other hand, work outside the home was life saving, particularly for one participant. Given this small sample size, this research theme could benefit from greater investigation into what role work plays in the lives of Filipina women who have experienced domestic violence.

\section{Gendered Migration and Domestic Violence}

Many Filipina professionals migrate to work as caregivers because of unemployment and poverty in the Philippines and a lack of financial resources necessary to become an immigrant in Canada (Constable, 1997). Further to this, that a Filipina woman is to be "mindful of the wellbeing of her family, primarily parents but also dependent siblings, fulfills one of the dictates of Philippine femininity. She is a dutiful daughter both in terms of the family and the Philippine state, which has calculated the export of gendered labour into its development policies" (Barber, 2000, p. 402). Jolly and Reeves (2006) discuss the consequences of such policies:

Experience shows that migration can provide new opportunities to improve women's lives and change oppressive gender relations - even displacement as a result of conflict can lead to shifts in gendered roles and responsibilities to women's benefits. However, migration can also entrench traditional roles and inequalities and expose women to new vulnerabilities as the result of precarious legal status, exclusions and isolation. (p. 1)

The cultural contexts that are layered into experiences of domestic violence make it difficult to settle on any unifactoral explanation (Guruge et al., 2010). Understanding the home country's economic and political contexts and cultural identities of gender may significantly inform our ability to understand how violence shows up in intimate relationships and may inform how we can best respond to it and support diverse communities:

This way of seeing migration from a development perspective is key to understanding the ways that violence occurs that is different than Canadian women who are not immigrants. There are still gaps in theory, policy and practice to see migration as gendered and developmental. International migration theories have failed to see gender specific migration, and in failing to see this, have subsequently failed in recognizing pre-departure domestic violence. The migration process is filled with possibilities, and hope for a better life, but for some Filipina women it can mean precarious legal status, abusive working conditions, social isolation and exclusion, and particular health risks and discrimination. (Jolly \& Reeves, 2006, p. 3)

Much attention is given to the socially defined roles of women, and in particular, ethnocultural women immigrating to Canada. However, there is also a need to understand the socially defined roles and cultural identities of men immigrating to Canada. Often the ethnocultural and socially defined roles of gender conflict with gender roles in Canada.

\section{Limitations}

Although this study generated valuable learning with respect to risk and protective factors within one community, the findings cannot be generalized due to only four interviews being conducted. Additionally, we were unable to recruit men from the Filipino community who had 
International Journal of Child, Youth and Family Studies (2013) 1: 147-165

actually perpetrated violence. Our contacts within the community were very clear that men were not willing to openly discuss their experiences. In hindsight, the chosen methodology was perhaps not conducive to generating discussion around such a sensitive topic for either women or men in the very short time frame available.

When working with men and women from newcomer communities in the future, we believe that a more participatory, conversational type of process would generate greater success in recruiting participants. Meeting with a set group over a period of three or four weeks could allow participants to gain trust with both the researchers and other participants, and could perhaps allow a fuller exploration of the process of violence. While this would entail a longer data collection process, we believe the results would be worth it.

\section{Conclusion and Recommendations}

There are several intersections between the interviews with the women and the focus group with the men; therefore the discussion and implications of the research is integrated to demonstrate and re-emphasize the interconnected and manifold nature of domestic violence. Further, the focus of the discussion can also be used to inform the provincial prevention and intervention strategy for domestic violence being informed by the Brenda Strafford Chair in the Prevention of Domestic Violence.

In regard to practice, there is a further need to address the gendered migration and cultural context of domestic violence. This may include:

1. Developing more complex settlement services that support the economic, social and family health of new Canadians during their transition to Canada, in order to avoid significant stresses that may contribute to family violence;

2. Ensuring that the staff of live-in caregiver resource centres can assist caregivers with information and legal support with respect to issues of domestic violence; and

3. Ensuring that key contacts within the individual's settlement country be provided at pre-migration orientation and upon arrival.

From this research, we learned that natural and/or cultural networks in Canada are key supports for domestic violence victims, and can therefore be positioned as strong protective factors within the community. In addition to educating formal settlement services and programs on risk factors and protective factors for domestic violence, greater effort is needed to leverage the existing formal and informal leaders or support workers within the community. This strategy would create a "community-made" solution preventing of domestic violence that captures the specific cultural contexts at play. This strategy would also include further consultation with particular faith communities and leaders to engage them in a lead role in prevention.

Specific to the Filipino community, additional research is needed to understand how the migration stressors of temporary foreign workers and live-in caregivers impacts migrants and may be significant risk factors for domestic violence. Future research that explores these "individualist factors" would be immensely valuable to understanding whether some women and men who migrate may be more vulnerable to domestic violence, and why. Offering post-arrival 
International Journal of Child, Youth and Family Studies (2013) 1: 147-165

orientation on migration stressors and gender equality may be one way of providing additional support in this area.

Finally, based on discussion with both the women and the referral group, there is a need to conduct further research into policies that may create and/or exacerbate vulnerabilities to domestic violence. Certain federal government initiatives, such as the Live-In Caregiver or Temporary Foreign Workers Programs, may create or exacerbate vulnerabilities through the forced separation of families for lengthy periods of time (Hodge, 2006). Reducing the time required for sponsorship would greatly support family stability and could be one way of reducing risk for domestic violence.

The migration process can have a profound impact and may facilitate or perpetuate vulnerabilities for violence in the lives of female and male newcomers. Jolly and Reeves (2006) argue that:

Theory, policy and practice that link gender equality concerns with migration from a development perspective are rare. Migration is still primarily seen as the corner of the state and migration as a development issue is only just emerging, with limited attention being paid to gender. (p. 38)

Without policy and directed funding to prevent domestic violence, the focus will continue to be on the crisis response model and domestic violence prevention will continue to be marginalized and not addressed within these systemic contexts. 
International Journal of Child, Youth and Family Studies (2013) 1: 147-165

\section{References}

Ahmad, F., Driver, N., McNally, M. J., \& Stewart, D. E. (2009). "Why doesn't she seek help for partner abuse?” An exploratory study with South Asian immigrant women. Social Science \& Medicine, 69(4), 613-622.

Almeida, R. V., \& Dolan-Delvecchio, K. (1999). Addressing culture in batterers intervention: The Asian Indian community as an illustrative example. Violence Against Women, 5(6), 654-683.

Andrew, C. (1998). Les Femmes et l'état-providence: Question revue et corrigée. Politique Et Sociétés, 17(1-2), 171-182.

Barber, P. (2000). Agency in Philippine women's labour migration and provisional diaspora. Women's Studies International Forum, 23(4), 399-411.

Brownridge, D. A., \& Halli, S. S. (2002). Double jeopardy? Violence against immigrant women in Canada. Violence and Victims, 17(4), 455-471.

City of Calgary. (2009). Volume 3: Calgary and region social outlook, 2009-2014 (The City of Calgary Land Use Planning and Policy). Calgary, AB: Author.

Constable, N. (1997). Maid to order in Hong Kong: Stories of Filipina workers. Ithaca, NY: Cornell University Press.

Denzin, N. (1984). Toward a phenomenology of domestic, family violence. America Journal of Sociology, 90(3), 483-515.

Flyvberg, B. (2001). Making social science matter: Why social inquiry fails and how it can succeed again. Cambridge, UK: Cambridge University Press.

Fortier, A. (1998). Gender, ethnicity and field work: A case study. In C. Seale (Ed.), Researching society and culture (pp. 48-57). Thousand Oaks, CA: SAGE Publications.

Frankl, V. (1984). Man’s search for meaning. New York: Simon \& Schuster.

Grewal, S., Bottorff, J., \& Hilton, B. (2005). The influence of family on immigrant South Asian women's health. Journal of Nursing, 11(13), 242-263.

Grossman, H. Y., \& Chester, N. L. (1990). Introduction: Learning about women and their work through their own accounts. In H. Y. Grossman \& N. L. Chester (Eds.), The experience and meaning of work in women's lives (pp. 1-10). Hillsdale, NJ: Lawrence Erlbaum Associates. 
International Journal of Child, Youth and Family Studies (2013) 1: 147-165

Gupta, J. (2009). Premigration exposure to political violence and perpetration of intimate partner violence among immigrant men in Boston. American Journal of Public Health (1971), 99(3), 462-469.

Guruge, S., Khanlou, N., \& Gastaldo, D. (2010). Intimate male partner violence in the migration process: Intersections of gender, race and class. Journal of Advanced Nursing, 66(1), 103-113.

Hodge, J. (2006). “Unskilled labour”: Canada’s live-in caregiver program. Undercurrent, 3(2), 60-66.

Jiwani, Y. (1997). Trapped: Holding on to the knife's edge: Economic violence against Filipino migrant/immigrant women. The Philippine Women's Centre of British Columbia. Vancouver, BC: The Feminist Research, Education, Development and Action Centre (FREDA).

Jolly. S., \& Reeves, H. (2006). Gender and migration: Overview report. Brighton, UK: Institute of Development Studies, University of Sussex.

Kasturirangan, A. (2008). Empowerment and programs designed to address domestic violence. Violence Against Women, 14(12), 1465-1475.

Kasturirangan, A., Krishnan, S., \& Riger, S. (2004). The impact of culture and minority status on women's experience of domestic violence. Trauma, Violence, \& Abuse: A Review Journal, 5(4), 318-332.

Lorenzetti, L., \& Este, D. (2010). War and partner violence: Refugee women's experiences and impacts on resettlement. Canadian Social Work, 12(1), 76-81.

Moran, D. (2000). Introduction to phenomenology. New York: Routledge.

Oxman-Martinez, J., \& Hanley, J. (2001, October). Border control as an approach to countering human trafficking. Presentation at Metropolis Conference, Ottawa, ON.

Public Health Agency of Canada. (2008). Intimate partner violence against immigrant and refugee women. Retrieved March 20, 2011 from http://www.phac-aspc.gc.ca/ncfvcnivf/EB/eb-Mar-2008-eng.php.

Sharma, A. (2001). Healing the wounds of domestic abuse: Improving the effectiveness of feminist therapeutic interventions with immigrant and racially visible women who have been abused. Violence Against Women, 7(12), 1405-1428.

Smith, E. (2006). Nowhere to turn? Responding to partner violence against immigrant and visible minority women. Ottawa: Canadian Council on Social Development. 
International Journal of Child, Youth and Family Studies (2013) 1: 147-165

Statistics Canada. (2006). Immigration in Canada: A portrait of the foreign born population, 2006 Census. Ottawa: Statistics Canada, Social and Aboriginal Statistics Division, Ministry of Industry.

Statistics Canada. (2010, March 9). The study of projections of the diversity of the Canadian population. The Daily. Retrieved March 20, 2011 from http://www.statcan.gc.ca/dailyquotidien/100309/dq100309a-eng.htm

Tutty, L. M, Giurgiu, B., Traya, N., Weaver-Dunlop, J., \& Christensen, J. (2010). Promising practices to engage ethno-cultural communities in ending domestic violence. Final Report to the Alliance to End Violence. Calgary, AB: RESOLVE Alberta.

Wells, L., Abboud, R., \& Claussen, C. (2012). Domestic violence in ethno-cultural communities: Risk and protective factors (Shift: The project to end domestic violence). Calgary, AB: The University of Calgary,

Williams, L., \& Yu, M. (2006). Domestic violence in cross-border marriage: A case study from Taiwan. International Journal of Migration, Health and Social Care, 2, 58-69.

Yoshihama, M. (2009). Appendix B: Literature on intimate partner violence in immigrant and refugee communities: Review and recommendations. In S. Novick (Ed.), Intimate partner violence in immigrant and refugee communities: Challenges, promising practices and recommendations (pp. 34-62). Princeton, NJ: Robert Wood Johnson Foundation. 